\title{
L'humanisme franco-canadien. Un cas, Benoit Lacroix, Atti del Convegno Internazionale 14-15 novembre 2005, a cura di Marina Zito
}

\section{Simona Rossi}

\author{
(2) OpenEdition \\ Journals \\ Edizione digitale \\ URL: http://journals.openedition.org/studifrancesi/9704 \\ DOI: $10.4000 /$ studifrancesi.9704 \\ ISSN: 2421-5856 \\ Editore \\ Rosenberg \& Sellier

\section{Edizione cartacea} \\ Data di pubblicazione: 1 décembre 2007 \\ Paginazione: 704-705 \\ ISSN: 0039-2944

\section{Notizia bibliografica digitale} \\ Simona Rossi, «L'humanisme franco-canadien. Un cas, Benoit Lacroix, Atti del Convegno Internazionale \\ 14-15 novembre 2005, a cura di Marina Zito», Studi Francesi [Online], 153 (LI | III) | 2007, online dal 30 \\ novembre 2015, consultato il 11 janvier 2021. URL: http://journals.openedition.org/studifrancesi/9704 \\ ; DOI: https://doi.org/10.4000/studifrancesi.9704
}

Questo documento è stato generato automaticamente il 11 janvier 2021.

\section{cc) (†) $\odot$}

Studi Francesi è distribuita con Licenza Creative Commons Attribuzione - Non commerciale - Non opere derivate 4.0 Internazionale. 


\title{
L'humanisme franco-canadien. Un cas, Benoit Lacroix, Atti del Convegno Internazionale 14-15 novembre 2005, a cura di Marina Zito
}

\author{
Simona Rossi
}

\section{NOTIZIA}

L'humanisme franco-canadien. Un cas, Benoit Lacroix, Atti del Convegno Internazionale 14-15 novembre 2005, a cura di Marina ZITo, Napoli, Università “L'Orientale", Facoltà di Lingue e Letterature Straniere, Dipartimento di Studi Americani, Culturali e Linguistici, 2007, pp. 190.

1 L'obiettivo di questo convegno (Università di Napoli, 2005) - del quale presentiamo qui gli atti - è piuttosto ambizioso e di "nobile" ispirazione: prendendo le mosse dall'opera di Benoît Lacroix, celebre intellettuale, storico, teologo e filosofo franco-canadese, i numerosi relatori si propongono, infatti, di rimettere l'uomo al centro di un nuovo "umanesimo" fondato sul dialogo interculturale. Benoît Lacroix ha cominciato a pubblicare i suoi lavori intorno agli anni Cinquanta del Novecento, ma scrive ancora agli albori del XXI secolo; le sue opere più celebri sono L'Histoire dans l'antiquité (1951) e Orose et ses idées (1965).

2 Pietro bogLioni studia il costante interesse che Benoît Lacroix ha dimostrato, nel corso della sua carriera, per la religione popolare, tema che, a suo avviso, è strettamente legato al concetto di umanesimo. Nella realtà del popolo franco-canadese delle origini la religione ha infatti un ruolo essenziale, in quanto fattore primario di costruzione di un culto dell'uomo fondato sulla «foi en l'éternité de[s] amours et de[s] ancêtres» (p. 11). Charles MOREROD, invece, inquadra l'umanesimo di Benoît Lacroix nel filone letterario domenicano, storicizzando le premesse di quest'ultimo e analizzando le sue 
peculiarità identitarie, che si basano sull'antica matrice medievale. Paolo cosenZA, dal canto suo, si dedica ad un fecondo confronto tra le teorie filosofi- che espresse da Lacroix e quelle di Aristotele, trovando un'oggettiva consonanza tra di esse e mostrando la loro incredibile attualità anche nell'epoca contemporanea. Gli altri partecipanti al convegno, infine, danno vita ad un affascinante dialogo tra la letteratura e la saggistica del passato e quelle odierne: tra gli altri, Marina ziTo nota una certa vicinanza spirituale e intellettuale di Lacroix con le opere di Saint-Denys Garneau, mentre Angela BUONO, Linda fASANO e Vincenzo IMPAGLIAZzo lo accostano a Marie-Claire Blais, Jacques Poulin e Lionel Groulx.

Tutte le comunicazioni, che non menzioniamo nello specifico per motivi di spazio, sono ugualmente interessanti: costituiscono un ponte articolato e originale tra l'opera di Lacroix e la poetica dell'essere e del nulla che caratterizza da sempre il dibattito intellettuale e lo stesso cammino interiore dell'uomo. La ricchezza dei temi trattati è notevole e non vengono tralasciati nemmeno i nuovi luoghi dell'umanesimo "moderno": lo spazio teatrale e quello cinematografico, che si materializzano nella presentazione di progetti creativi e documentari sulla vita e sulla scrittura di Benoît Lacroix. Segnaliamo anche la presenza di una bibliografia selettiva dell'autore, alla fine del volume, che ci sembra di particolare interesse.

4 Capaci di trovare il giusto equilibrio tra il territorio filosofico "classico" e quello più strettamente legato alla quotidianità e ai grandi interrogativi che animano il pensiero umano, questi atti costituiscono senza alcun dubbio un testo rilevante, testimone non solo della vivacità - e complessità - dell'opera di Benoît Lacroix, ma anche di un momento importante di dialogo e scambio nel cammino culturale del Québec odierno. 